\title{
Optimization of Steam Distribution Network at the Cooking Plant: Experimental and Numerical Study
}

\author{
Farzad Hekmatipour' ${ }^{1}$ Milad Jalali² and Farhad Hekmatipour ${ }^{3 *}$ \\ 'School of Mechanical Engineering, College of Engineering, Islamic Azad University Kashan Branch, Kashan, Iran; \\ f.hekmatipour@gmail.com \\ ${ }^{2}$ Faculty of Physics, Semnan University, Semnan, Iran; \\ milad_5984@yahoo.com \\ ${ }^{3}$ Department of Energy and Environment, Science and Research Branch, Islamic Azad University, Tehran, Iran; \\ farhad.hekmatipour@srbiau.ac.ir
}

\begin{abstract}
Objectives: The distribution of steam networks at cooking plant is determined experimentally and numerically in this research. Methods: Both methods of numerical and experimental study was carried out on the optimization of oxygen, steam load as well as stack temperature. The gadgets used for empirical study were combustion gases, stack gas temperature sensor, steam flow meter, and Oxygen $\left(\mathrm{O}_{2}\right)$ sensors. GAMS software and EVIEWS software were used to model and optimize the steam network. The result of numerical and experimental was compared and the evaluation was presented. Findings: Experimental study shows that the steam networks decrease dramatically in a boiler and once illustrates that steam network arrived zero in a boiler. This circumstance expresses two boiler can be determined 79931.28 and 77350.36, respectively. The sum of two boilers is $157281.64 \mathrm{~kg} / \mathrm{s}$. This condition leads to decreasing the energy consumption in an empirical result. The amount of energy consumption in two boiler arrived 84437.47 and 54321.63, respectively. The sum of the energy consumption was $138759.1 \mathrm{Kw}$. The numerical model shows that both steam load declined 78471.41 and 77786.49, respectively. Energy consumption in two boilers decline to reach 84580.31 and 53514.77, respectively. Application: We compared the experimental and numerical model in this project. The deviation of the experimental and numerical model is less than $8 \%$. It means the results are reliable and the model can be used for simulation of the steam load in process engineering in small industries. The operating cost decreases up to 167686882.9 per annum. The best way to improvement is the use of NMLP in this project because the NMLP has more reliable.
\end{abstract}

Keywords: Controlling Steam Volume, Furness, Optimization, Process Engineering

\section{Introduction}

Nowadays, steam networks are widely used in several industrial applications such as petrochemical, cooking plant, power plant, heating, air-conditioning and oil and gas. Therefore, controlling steam load can be effective on the reduction of fuel waste and heat losses in industrial applications. Another reason is the increment of operating costs because the cost of fuel increases dramatically over the two last decades. It is acceptable that the cost of energy influences on productive price and profit and it seems to reduce return cost if the productive price is constant. Thus, optimization and simulation can be used asa method in order to control several items in steam and hot water networks. Many researchers worked on the optimization of the utility system in power plants.

${ }^{*}$ Author for correspondence 
MINLP method was used to be introduced a new model for steam and gas in optimizing system operation and design 1 . A mixed-integer linear programming is used to optimize the synthesis of processing systems $s^{2}$. This approach was applied to the synthesis of utility systems that had to provide fixed demands of electricity, power for drivers and steam at various pressure levels ${ }^{3}$. A systematic methodology was presented to minimize the total cost under normal conditions while reserving enough flexibility and safety for unexpected equipment failure conditions ${ }^{3}$. The proposed method transforms the different conditions into real periods to indicate normal scenarios and virtual periods to indicate unexpected equipment failure scenarios. The optimization strategy was presented to save costs and guarantee operation safety ${ }^{3}$. A Multi-objective Mixed Integer Nonlinear Programming (MOMINLP) model was applied to determine the equipment type (cogeneration system and emission abatement technology), equipment number, equipment design capacity and equipment operation load while simultaneously combining multiple objectives of minimization of economic cost, minimization of environmental effect and maximization of exergy efficiency ${ }^{4}$. A novel integrated approach was proposed to optimize process production planning and utility system operation simultaneously. A refinery-wide mixed integer nonlinear programming model is proposed and the traditional method and improved integrated method are compared 5 . The model was able to use for the isentropic efficiency of the decomposed simple turbines. Controlling model is introduced to optimize .The thermodynamic properties of steam and water regressed through linearization of piecewise linearization. The second comparison between the simulated results using the proposed model and the data in working condition diagram provided by the manufacture is conducted over a wide range of operations. The simulation result yields a small deviation from the data in the working condition diagram where the maximum modelling error is $0.87 \%$ among the compared seven operation conditions ${ }^{6}$. A new algorithm was defined to optimize the utility system in power plant ${ }^{7}$. An examination was reported of the effect of equipment reliability on the exergo-economic analysis and optimization of site utility system. A genetic algorithm on hybrid techniques was used in order to determine optimum solution ${ }^{8}$. Utility optimization system has been conducted by using mixed integer linear programming and all possible operational models and various types of objective functions have been considered to minimize the flexibility and usefulness of the optimization system? ${ }^{9}$. The main objective of motor/turbine process was to manipulate optimal balance on steam and electricity in utility plants. The optimal operation of motor/turbine process, steady state model for steam generation equipment and steam distribution devices as well as turbine generators were developed and analysed ${ }^{10}$. The combination of the optimization of utility system performance with reliability theory based on Markov analysis was performed ${ }^{11}$. The cost of the steam power system for all period was considered to define a new algorithm for optimization of steam power system ${ }^{12}$. A hybrid model for the steam turbines of a utility system is developed by using neural networks model with the thermodynamic model ${ }^{13}$. A Mixed-integer Nonlinear Programming (MINLP) model based on an improved modelling principle of the complex turbine was formulated for the operation optimization of ICSTUN. The MINLP model was able to simultaneously optimize the external and internal utility networks. The optimization of a single utility plant yields a maximum coal reduction rate of $4.59 \%$ and the optimization of the total utility system consisting of two utility plants yields a maximum coal reduction rate of $6.01 \%{ }^{14}$. A Mixed-integer Nonlinear Programming (MINLP) model was formulated to perform the operation optimization. The proposed model considers electric power as the alternative energy source for lower-level mechanical power demands. Using the proposed optimization model on the ethylene plant, a maximum of $8.01 \%$ reduction in the total operation cost is achieved compared with original operation strategies ${ }^{15}$. A Mixed-integer Linear Programming (MILP) formulation was presented for synthesis and operational planning of utility system for multi period operation with varying demands ${ }^{16,17}$. A Mixed-integer Linear Programming model is developed which includes four parts: Production planning for materials, energy requirements of process units on the basis of pinch analysis, operational planning for utility systems and balance of utility streams in total sites. A coupling mixed integer nonlinear programming model is presented in this work to integrate process plants and utility systems; the objective is to minimize the energy costs to meet the requirements of the process operations and to maintain a steam balance in the total site ${ }^{18,19}$. An investigation in the optimization of a steam turbine CHP (Combined Heat and Power) system under three economic cases resulting from the introduction of a carbon price in Australia has been conducted ${ }^{20}$. Complex mathematical models which to screen the alternatives that constitute accurate and reliable process mode are applied to perform a synthesis and design of chemical process ${ }^{21}$. The mathematical methods were used 
to be optimized the carbon dioxide and operating $\cos \mathrm{t}^{22-24}$. Optimization of integrated network for utility supply is conducted to reduce the amount of carbon dioxide ${ }^{25,29}$. Minimizing energy cost was main reason for conduction of optimization in Refinery and petrochemical industries ${ }^{30,33}$. Multi-objective optimization methods which were used for energy saving are reviewed ${ }^{34}$. Load for boilers, gas turbines, steam turbines, condensers were optimized in power plant $\frac{35}{3}$. Heat Integration (TSHI) was used to optimize the utility synthesis for the total site ${ }^{36}$. This investigation is unique because the majority of studies were conducted in the petrochemical industry and power plant. Although, the optimizing process can be effective on the reduction of emitting $\mathrm{CO}_{2}$ and the reduction of the operating cost. The aim of this research is to present a new numerical model with MILP and experimental investigation in order to compare numerical model with experimental data at the cooking plant. In this paper, developed MILP algorithm is introduced to optimize steam boilers network at the cooking plant. The model which is introduced is based on the optimal excess oxygen, efficiency, boiler load and fuel impute in process. The reduction of energy cost and operating cost at a cooking plant is the main target in this optimization.

\section{Problem Description}

The boilers which are using industrial applications, especially cooking plant, should be on-line all the time. Consequently, the consumption of energy increases at the cooking plant. Another reason is that the boilers need a reserve when a boiler is failed in the process. Although it is acceptable that using reserves boilers increase investment cost due to the stable energy which is used in different parts of the utility system. Optimization can be a method to decrease the investment cost and operating cost in utility system since it is possible to optimize steam and heating load in utility system based on the consumption of oxygen, carbon dioxide and energy cost. In this research, a scenario is defined to optimize the steam load based on excess air and fuel inputs. Due to the assessment of Mixed-integer Linear Program, the experimental study is presented to compare with numerical model. The second scenario is the comparison of the experimental result with data which are reported by manufacture. The majority of research conducted to optimize the steam in turbine and boiler networks have not compared with experimental result because the research will be expensive. Although utility system used in this project is relatively small and the research focuses on the steam load and reduction of incomplete combustion because a part of fuel is emitted to atmosphere in boilers and furnaces. Indeed, incomplete fuel emitted to atmosphere has more hazardous effect than carbon dioxide on atmosphere. The reduction of excess air in combustion gases shows that combustion is complete. This important factor should be considered in utility systems.

This simulation focuses on the reduction of excess air in combustion gases and energy cost in order to enhance energy efficiency which can be effective on the declination of greenhouse gases emission.

\section{Experimental Implementation}

In this research, the experimental investigation and manufacture data are used to determine the characteristics of boilers at the cooking plant located in Tabas in Iran. Three boilers which use gas burner in the cooling plant are illustrated schematically in Figure 1. The main fuel line used to build steam in boilers is $0.122 \mathrm{~m}^{3} / \mathrm{s}$ and the steam load boilers are $156492 \mathrm{~kg} / \mathrm{hr}$. The characteristics of boilers are presented in Table 1. The efficiency of boilers based on steam load, the percent of oxygen in combustion gases and stack temperature are reported in Table 1. It is observed that maximum of efficiency and steam mass flow rate $85 \%$ and $90720 \mathrm{~kg} / \mathrm{hr}$ occurred in first boiler.

\subsection{Instruments}

In order to measure the stack temperature, steam mass flow rate and excess air in combustion gases, stack gas temperature sensor, steam flow meter and Oxygen $\left(\mathrm{O}_{2}\right)$ sensors were applied in this research. Indeed, the characteristics of three pumps, three flow meters, three oxygen sensors, thermocouple applied are presented in

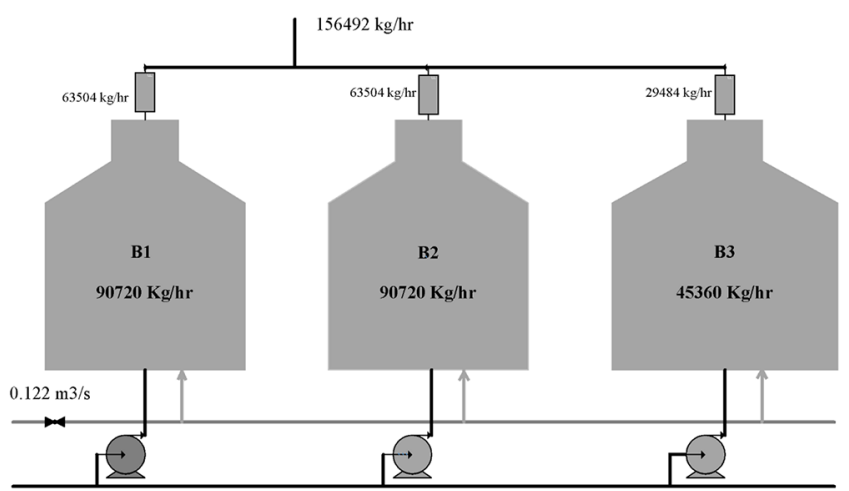

Figure 1. Schematic boilers network. 
Table 1. Characteristics of the boilers

\begin{tabular}{|c|c|c|c|c|c|c|}
\hline Boiler & $\begin{array}{c}\text { Mass flow rate } \\
(\mathrm{kg} / \mathrm{hr})\end{array}$ & $\begin{array}{l}\text { Stack temerature } \\
\left({ }^{\circ} \mathrm{C}\right)\end{array}$ & $\begin{array}{l}\text { Measurement } \\
\text { Oxygen (\%) }\end{array}$ & $\begin{array}{l}\text { Efficiency of } \\
\text { combustion }\end{array}$ & $\begin{array}{c}\text { Heat } \\
\text { imput }(\mathrm{Kw})\end{array}$ & $\begin{array}{c}\text { Energy } \\
\text { output }(\mathrm{Kw})\end{array}$ \\
\hline \multirow[t]{4}{*}{1} & 90720 & 151.7 & 2 & 85 & 77993.91 & 66299.22 \\
\hline & 77112 & 97.8 & 2 & 86 & 65537.16 & 56363.13 \\
\hline & 58968 & 148.9 & 7 & 84 & 51292.5 & 43085.7 \\
\hline & 45360 & 137.8 & 12 & 81.5 & 40682.28 & 33149.61 \\
\hline \multirow[t]{5}{*}{$2 u$} & 90720 & 329.44 & 2 & 77.5 & 85292.1 & 66299.22 \\
\hline & 6. & 5. & 4. & 3. & 2. & 1. \\
\hline & 77112 & 298.9 & 4 & 78 & 72249.15 & 56363.12 \\
\hline & 58968 & 271.11 & 7 & 77 & 55952.79 & 43085.7 \\
\hline & 45360 & 254.44 & 11 & 74 & 44785.68 & 33149.6 \\
\hline \multirow[t]{4}{*}{3} & 45360 & 315.5 & 2 & 78 & 42499.5 & 33149.61 \\
\hline & 38556 & 298.9 & 2 & 78.5 & 35904.75 & 28166.91 \\
\hline & 29484 & 282.22 & 7 & 76.5 & 28166.99 & 21542.88 \\
\hline & 22680 & 260 & 11 & 73.5 & 22539.39 & 16589.46 \\
\hline
\end{tabular}

Table 2. The measurement of the stack gas temperature in the boilers is made by using two K-type adhered to thermometer which is utilised with the accuracy of $\pm 0.1^{\circ} \mathrm{C}$. The assemblage of the RTD sensors was specific to sense the temperature of combustion gases at the stack. The position of two K-type thermocouples with the TPI343 sensor was inlet stack because sensors measured temperature of centre stack.

The measurement of oxygen is conducted by using ZKM oxygen transmitter with accuracy of $\pm 0.5 \%$ and detector ZKF8. The use of Rosemount 8800 Series Vortes Flowmeter measured the steam flow rate. The accuracy of steam flowmeter was $\pm 2.0 \%$ to $6.0 \%$.

In order to present appropriate data, the FILR E-60 is applied to measure the temperature of outside stacks and boilers in this investigations. The accuracy of thermal carmer was $\pm 0.05^{\circ} \mathrm{C}$ at $30^{\circ}$.

Measuring analytic uncertainty of stack temperature and heat input was presented according to the comparison with manufacturer' data, and the maximum error of the heat flux and stack temperatue were $8 \%$ and $7 \%$, respectively.

\section{Methodology}

In this work, two experimental and numerical model are used to determine the result of numerical and experimental reasults. Because the evaluation of the numerical model should be experimental investigatedand improved of the maximum error and deflection of numerical and experimental result.

\subsection{Experimental data}

In order to evaluate the numerical model, experimental data is obtained to investigate the accuracy of MILP model in this work. By using stoichiometry, the flue input is calculated based on the characteristics of natural gas in Iran. The heat input in boiler and boiler efficiency are calculated with Equation 1, it follows ${ }^{37}$ :

$$
\begin{gathered}
Q_{\text {in }}=Q_{\text {fuel }}+Q_{\text {fuelphysical }}+Q_{\text {in }}+Q_{\text {other }} \\
\dot{Q}_{\text {in }}=B \cdot\left(\begin{array}{c}
H_{i}+\lambda \propto_{l o^{\prime}} \cdot C_{\text {pair }} \cdot \\
\left(t_{\text {air }}-t_{\text {amb }}\right)+C_{\text {fuel }} \cdot\left(t_{\text {fuel }}-t_{\text {amb }}\right)
\end{array}\right)+\dot{Q}_{\text {other }}
\end{gathered}
$$

Table 2. Specification of the instruments

\begin{tabular}{|l|c|c|c|}
\hline \multicolumn{1}{|c|}{ Property } & Instrument & Range & Accuracy \\
\hline Stack Gas Temperature & K-type thermocuple & -58 to $999^{\circ} \mathrm{C}$ & $\pm 0.1^{\circ} \mathrm{C}$ \\
\hline Stack oxygen $\left(\mathrm{O}_{2}\right)$ & Oxygen $\left(\mathrm{O}_{2}\right)$ & -20 to $1500^{\circ} \mathrm{C}$ & $\pm 0.5 \%$ \\
\hline Steam flow rate & Gas/Steam flow meter & $0.1 \mathrm{~m}^{3} / \mathrm{hr}$ to $1395 \mathrm{~m}^{3} / \mathrm{hr}$ & $\pm 2.0 \%$ to $6.0 \%$ \\
\hline
\end{tabular}




$$
\begin{gathered}
\lambda=\frac{\text { Airactuallyuse }}{\text { Airstichiometricallynecessary }}=\frac{A}{A_{o}} \\
Q_{\text {in }}=Q_{\text {useful }}+Q_{\text {loss }} \\
Q_{u s e f u l}=Q_{\text {in }}-Q_{\text {loss }} \\
Q_{\text {useful }}=m \cdot\left(h_{\text {out }}-h_{\text {in }}\right) \\
\eta_{\text {boiler }}=\frac{\dot{Q}_{u s e f u l}}{\dot{Q}_{\text {in }}}=1-\frac{\dot{Q}_{\text {loss }}}{\dot{Q}_{\text {in }}}
\end{gathered}
$$

The characteristics of gas and weather condition are presented in Tables 3 and $4^{\frac{38}{8}}$. In addition, the specification of air and natural gas are reported in Table 5. Figures 2 and 3 show the fuel input in boiler and boiler efficiency to determine the performance of boilers in this article. According to the experimental data, the heat imputed and

Table 3. Specification for CNG

\begin{tabular}{|l|c|}
\hline Components & Prencentage (\%) \\
\hline $\mathrm{H}_{2}$ & $50 \%$ \\
\hline $\mathrm{CH}_{4}$ & $20 \%$ to $30 \%$ \\
\hline $\mathrm{CO}$ & $7 \%$ to $17 \%$ \\
\hline $\mathrm{CO}_{2}$ & $3 \%$ \\
\hline $\mathrm{N}_{2}$ & $8 \%$ \\
\hline Hydrocarborns & $8 \%$ \\
\hline
\end{tabular}

efficiency of boiler is presented in Figure 1. According to the result, it shows that experimental data are compared with characteristics of boilers in Figure 2. The minimum and maximum energy input are obtained $20341 \mathrm{Kw}$ and $85000 \mathrm{Kw}$ in second and third boiler, respectively. The result shows that the maximum error of experimental result is $8 \%$. It is an accurate error from numerical investigation and the experimental investigation is reliable in this research job. The comparison of experimental efficiency of boilers with boiler characteristics is plotted in Figure 3. The result illustrates that minimum and maximum efficiency were $73 \%$ and $86 \%$ in boiler 3 and 2 , respectively. The maximum deflection of experimental result with characteristics of boiler is $9 \%$. Thus, the accuracy of experiment is relatively appropriate because the experimental investigation was applied to determine the primary characteristics of boilers in steam network and it can be used for evaluation of optimization and MILP model presented in article.

In order to measure the boiler characteristics at cooking plant, experimental investigation has been performed in this research job. The experimental result is presented in Table 6 . The energy inputs of boilers increase up to $59792 \mathrm{Kw}$ in second boiler and the efficiency of boiler rise up to $85 \%$. Stack temperature also increases up to $282^{\circ} \mathrm{C}$. The range of experimental data measured is reported in Table 7. This range is used for simulation in this article because the range of different factors should be defined in MILP model.

Table 4. Weather condition of Tabas

\begin{tabular}{|c|c|c|c|c|c|c|c|c|c|c|c|c|}
\hline & Jan. & Feb. & Mar. & Apr. & May & Jun. & Jul. & Aug. & Sep. & Oct. & Nov. & Dec. \\
\hline Avg. T $\left({ }^{\circ} \mathrm{C}\right)$ & 7.9 & 10.8 & 16.3 & 20.2 & 26.6 & 31.6 & 33.6 & 33.9 & 28 & 22 & 14.7 & 8.7 \\
\hline Min. T $\left({ }^{\circ} \mathrm{C}\right)$ & 1 & 4.1 & 10 & 12.8 & 18.7 & 23 & 25.4 & 23.4 & 18.6 & 13 & 6.3 & 1 \\
\hline Max. T $\left({ }^{\circ} \mathrm{C}\right)$ & 14.8 & 17.5 & 22.7 & 22.7 & 34.5 & 40.3 & 41.9 & 44.4 & 37.4 & 31.4 & 23.1 & 16.5 \\
\hline Avg. T $\left({ }^{\circ} \mathrm{C}\right)$ & 46.2 & 51.4 & 61.3 & 68.4 & 79.9 & 88.9 & 92.5 & 93.0 & 82.4 & 72.0 & 58.5 & 47.7 \\
\hline
\end{tabular}

Table 5. Specification of gas and air

\begin{tabular}{|c|c|c|c|}
\hline Air Properties & Value & Gas Properties & Value \\
\hline $\mathrm{Cp}(\mathrm{KJ} / \mathrm{Kg} . \mathrm{K})$ & 1.01 & $\mathrm{Cp}(\mathrm{KJ} / \mathrm{Kg} . \mathrm{K})$ & 2.34 \\
\hline $\mathrm{Cv}(\mathrm{KJ} / \mathrm{Kg} . \mathrm{K})$ & 0.718 & $\mathrm{Cv}(\mathrm{KJ} / \mathrm{Kg} . \mathrm{K})$ & 1.85 \\
\hline$\propto_{l 0^{\prime}}$ & 14.981 & Gas flow rate $\left(\mathrm{m}^{3} / \mathrm{s}\right)$ & 0.122 \\
\hline & $\mathbf{8 .}$ & Gross heat values $(\mathrm{kcal} / \mathrm{kg})$ & 10000 to 12000 \\
\hline 7. & 10. & Net heating values $(\mathrm{kcal} / \mathrm{kg})$ & 9000 to 11000 \\
\hline 9. & 12. & Pressure $($ bar $)$ & 0.017 to 20.68 \\
\hline 11. & 14. & temperature & $0^{\circ} \mathrm{C}$ \\
\hline 13. & & &
\end{tabular}


Table 6. Characteristic of boilers

\begin{tabular}{|c|c|c|c|c|c|c|}
\hline Boiler No. & Size Boiler (kg/hr) & Normal Boiler Load & \multirow{2}{*}{ Heat Input Kw } & \multicolumn{2}{|c|}{ stack } & \multirow{2}{*}{ Unit. Efficiency } \\
\cline { 4 - 6 } & & & & Stack Temp. $\left({ }^{\circ} \mathrm{C}\right)$ & $\mathrm{O}_{2}(\%)$ & \\
\hline 1 & 90720 & 63504 & 54516.6 & 143.3 & 5 & 85 \\
\hline 2 & 90720 & 63504 & 59792.4 & 282.2 & 6 & 77.4 \\
\hline 3 & 45360 & 29484 & 28137.6 & 282.2 & 7 & 76.5 \\
\hline Sum & 18. & 156492 & 142446.6 & 17. & 16. & 15. \\
\hline
\end{tabular}

Table 7. The range of experimental data

\begin{tabular}{|c|c|c|c|c|c|}
\hline \multicolumn{2}{|c|}{ Steam load } & \multicolumn{2}{c|}{ Stack temperature (C) } & \multicolumn{2}{c|}{ Output Oxygen (\%) } \\
\hline Minimum & Maximum & Minimum & Maximum & Minimum & Maximum \\
\hline 0 & 90720 & 0 & 154.44 & 0 & 11 \\
\hline 0 & 90720 & 0 & 371.11 & 0 & 11 \\
\hline 0 & 45360 & 0 & 371.11 & 0 & 11 \\
\hline
\end{tabular}

\subsection{Numerical Model}

\subsubsection{Equations}

This model is designed with steam load, excess air, stack temperature and exhaust. This is due to the model considered different type of factors, which can be effective on the reduction of energy input, carbon mono oxide and water consumption in steam network. The objective unit considered in this work is steam load which can be effective on the reduction of water consumption and carbon dioxide because the location of cooking plant is in Tabas which has dry and hot weather in Iran. The equation of steam load is presented as it is followed:

$$
\min B=\sum B_{i}
$$

Where $\mathrm{B}$ is total boilers gas consumption and $\mathrm{B}_{\mathrm{i}}$ is boiler coal consumption.

Constraint functions are applied to reveal the relationship between each boiler gas feeding to evaporation in boilers. Gas consumption and evaporation are calculated, as in:

$$
\begin{gathered}
B=f\left(X_{i}\right) \\
B_{i}=a_{0}+a_{1} X_{i}+a_{2} X_{i}^{2}+\ldots+a_{n} X_{i}^{n} \\
X_{i_{\text {min }}} \leq X_{i} \leq X_{i_{\text {max }}}
\end{gathered}
$$

Where $\mathrm{B}$ is total gas consumption, $\mathrm{X}_{\mathrm{i}}$ is steam load of boiler, $\mathrm{B}_{\mathrm{i}}$ is boiler, $\mathrm{X}_{\min }$ is minimum and $\mathrm{X}_{\max }$ is maximum steam outlet of each boiler.
The relation between oxygen and gas consumption is obtained by using Equation 12:

$$
\eta_{i}=C_{0}+C_{1} X_{i}+C_{2} X_{i}^{2}+\ldots+C_{n} X_{i}^{n}
$$

Where $\eta$ is boiler efficiency and $x_{i}$ is steam outlet of boiler.

$$
O_{2 i}=e_{0}+e_{1} A_{0}+e_{2} A_{0}^{2}+\ldots+e_{n} A_{0}^{n}
$$

Where $\mathrm{A}_{\mathrm{o}}$ is excess air and $\mathrm{O}_{2 \mathrm{i}}$ is oxygen.

The equation used for simulation of stack temperature is reported as it is followed:

$$
\eta_{i}=d_{0}+d_{1} A_{0}+d_{2} T_{s}
$$

Where $\mathrm{A}_{\mathrm{o}}$ is excess air and $\mathrm{T}_{\mathrm{s}}$ is stack temperature.

The amount of excess air depends on complete combustion; as a consequent, the reduction of excess air can be effective on the reduction of heat losses. Another factor can be influential on the reduction of energy input is stack temperature in boilers and furnaces. This model is sought to be optimized the stack temperature and excess air in boilers based on steam load in steam networks.

\section{Result}

In order to optimize the steam load and energy input in steam network, we used MILP programming and GAMS software and EVIEWS software to defined a new model in steam network. In this article, the numerical result is compared with the experimental data. Constant parameter is calculated using EVIEWS software and 

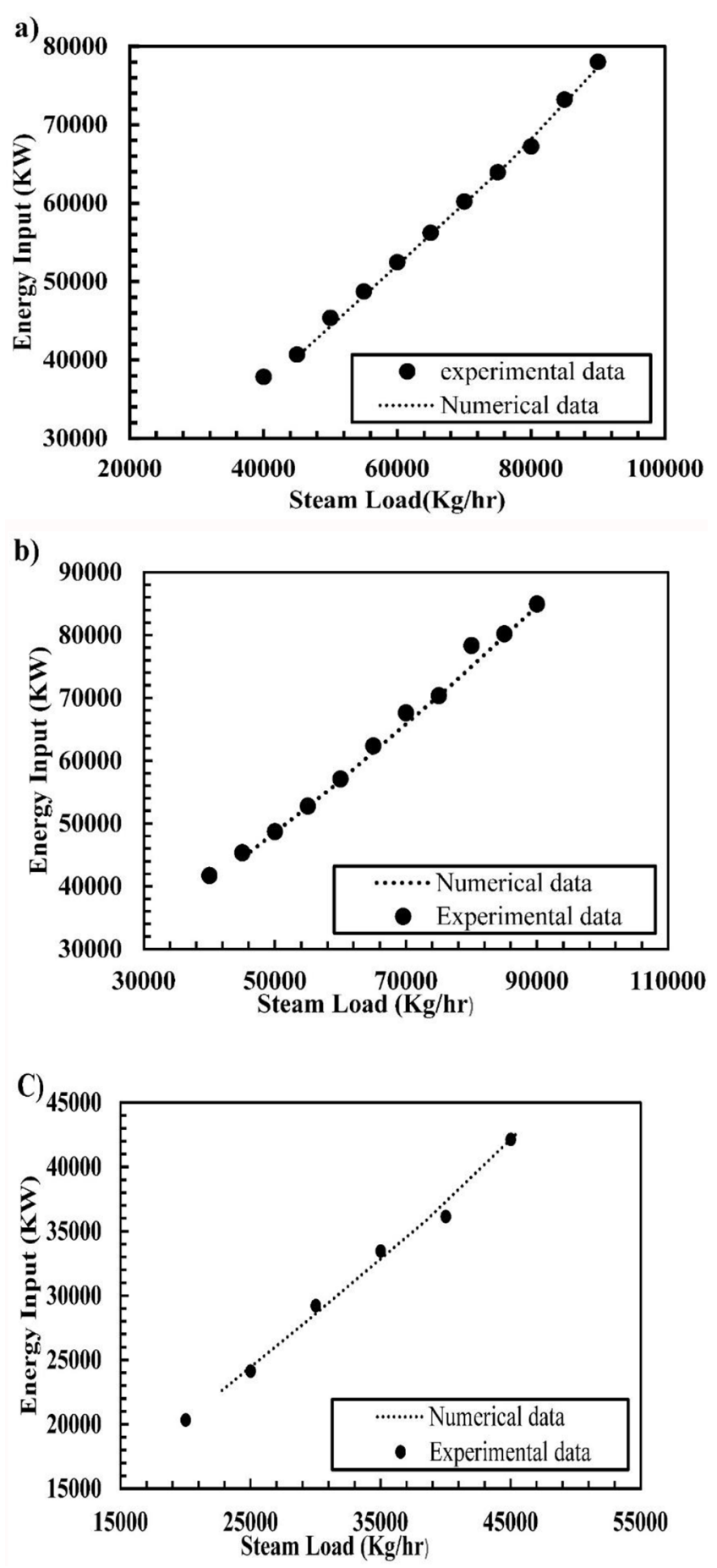

Figure 2. Comparison experimental energy input with characteristics of boilers a) Boiler 1, b) Boiler 2 and c) Boiler 3.

experimental data. Thus, the constants are accurate to use for simulation. The overall methodology for the optimal synthesis and optimization of utility system is shown in Figure 4 . The target is the determination of minimum steam load in steam network. The evolution algorithm and model evolution are interactively performed in the
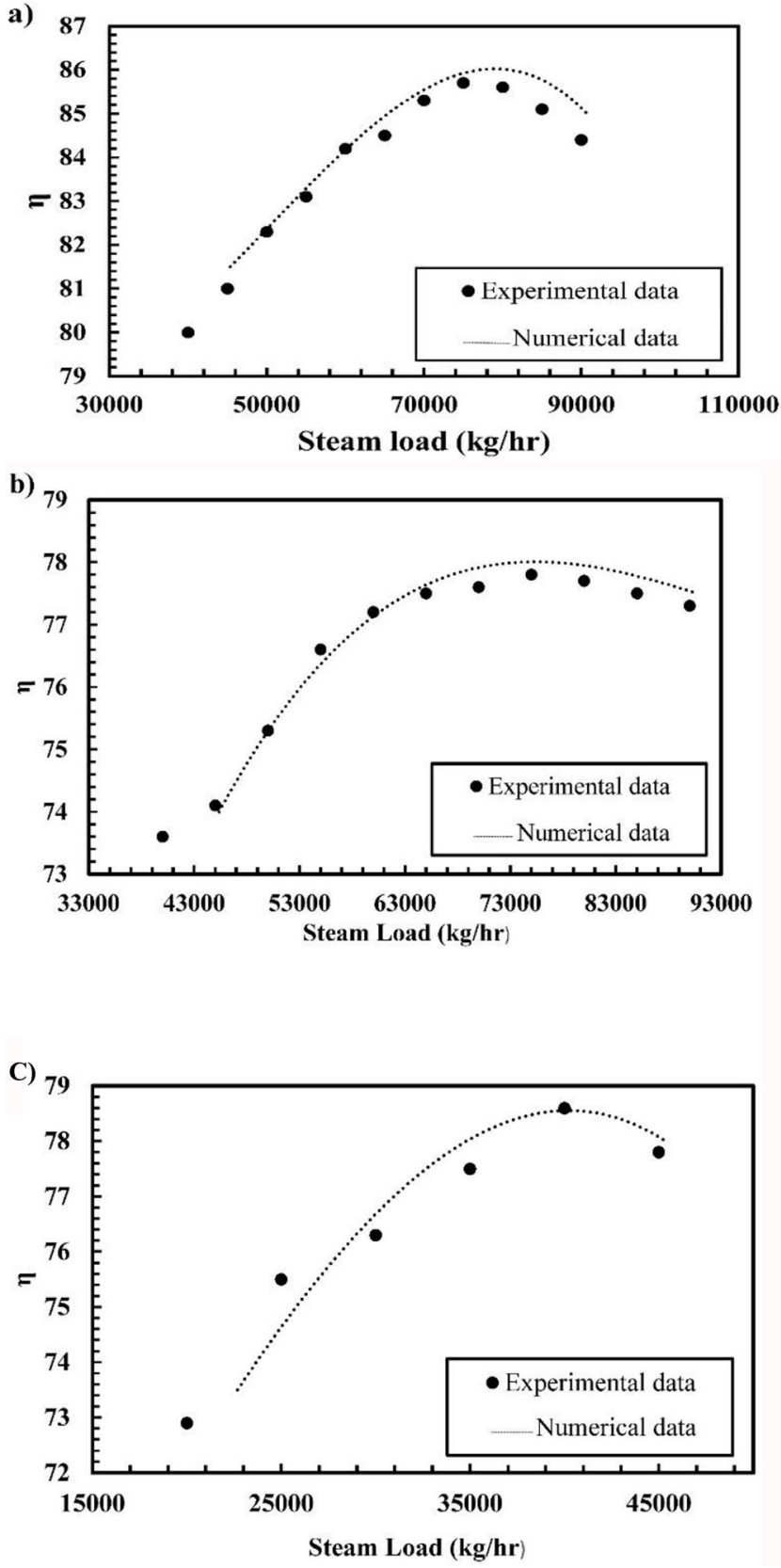

Figure 3. Comparison of the experimental efficiency with characteristics of boilers a) Boiler 1, b) Boiler 2 and c) Boiler 3.

calculation, which ensures the feasibility of configuration and improves the computational efficiency.

The equations applied in this model are presented as it is followed:

$$
\begin{gathered}
B_{1}=66.695+3.191 X_{1}-0.01507 X_{1}^{2}+3.72 \\
B_{2}=40.072+0.89 X_{2}-0.0048 X_{2}^{2}+7.51 \times 10^{-6} X_{2}^{3} \\
B_{2}=40.072+0.89 X_{2}-0.0048 X_{2}^{2}+7.51 \times 10^{-6} X_{2}^{3}
\end{gathered}
$$




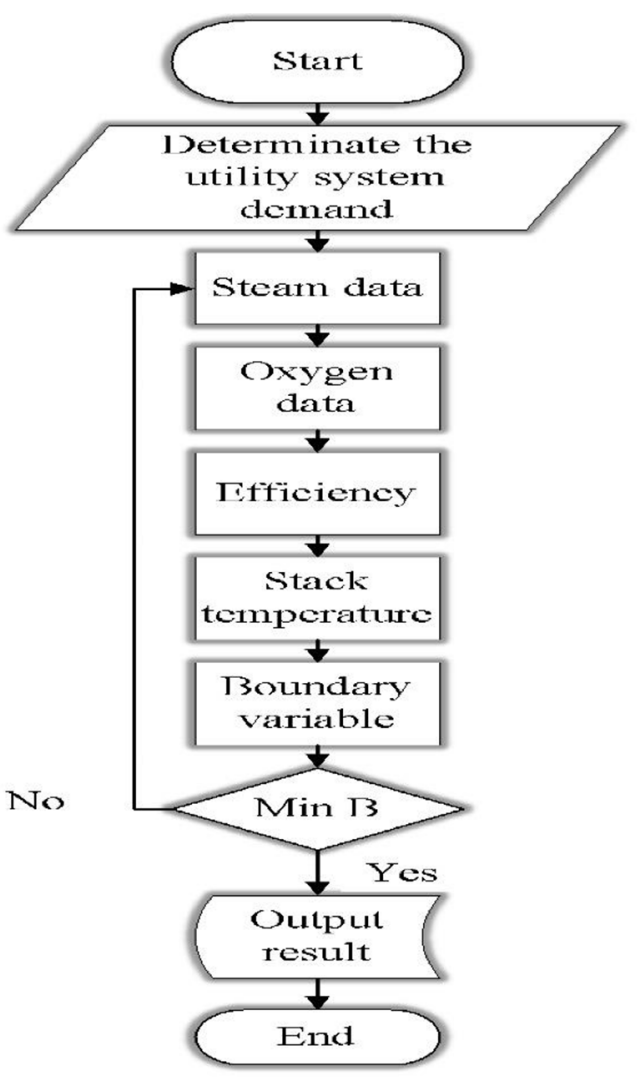

Figure 4. Flowchart.

$$
X_{i_{\min }} \leq X_{i} \leq X_{i_{\max }}
$$

Where $\mathrm{B}_{\mathrm{i}}$ is boiler, $\mathrm{X}_{\min }$ is minimum and $\mathrm{X}_{\max }$ is maximum steam outlet of each boiler.

The equations calculated for efficiency is reported as it is followed:

$$
\begin{gathered}
\eta_{1}=-86.024+0.265 X_{1}-0.00306 X_{1}^{2}+8.83 \times 10^{-6} X_{1}^{3} \\
\eta_{2}=40.072+0.894 X_{2}-0.003063 X_{2}^{2}+4.99 \times 10^{-6} X_{2}^{3} \\
\eta_{3}=59.59+0.264 X_{3}-0.00134 X_{3}^{2}+2.14 \times 10^{-6} X_{3}^{3}
\end{gathered}
$$

Efficiency function versus excess air and external gas temperature is achieved, is as follows:

$$
\eta_{n}=94.136+0.125 A_{n}-0.0816 T_{n}
$$

Where $\mathrm{A}$ is excess air, $\mathrm{T}$ stack temperature and $\mathrm{n}$ is number of boilers.

Oxygen which is on external gas versus value excess air is obtained, is as follows:

$$
O_{2_{n}}=0.0313-0.214 A_{n}-0.0014 A_{n}^{2}-3.51 \times 10^{-6} A_{n}^{3}
$$

Where $\mathrm{A}_{\mathrm{o}}$ is excess air and $\mathrm{O}_{2 \mathrm{n}}$ is oxygen.

In addition, one constraint is used as a controller, that total steam load is as follows:

$$
F=X_{1}+X_{2}+X_{3}
$$

Table 8 is presented to determine a new model based on excess air and stack temperature in cooking plant. The performance of third boiler is not needed since the steam load is provided by using two boilers. It can be used as reserve boiler. Indeed, energy consumption can be decreased by controlling inputs and outputs of boilers which are parallels and series. The temperature of stacks increases due to the improvement of combustion efficiency in boilers. As a result, the fuel consumption declined due to use of economizer and water preheating in stacks.

\section{Discussion}

This experimental study has been conducted to validate the numerical model and analyse the result of model. The similar condition is created in experimental investigation to determine the fuel consumption and water consumption in three boilers. The experimental result is shown in Table 9. The comparison between numerical and experimental investigation illustrates that the maximum error of steam load in first and second boilers were approximately $2 \%$ and $1 \%$, respectively. The maximum error of energy input in first and second boilers were almost $0.05 \%$ and $1.5 \%$, respectively. The deflection of stack temperature is about $4 \%$ in boilers. Based on Tables 8 and 9, the deviation of numerical efficiency and experimental efficiency is

Table 8. Results of simulations

\begin{tabular}{|c|c|c|c|c|c|c|}
\hline \multirow{2}{*}{$\begin{array}{c}\text { Number of } \\
\text { boiler }\end{array}$} & $\begin{array}{c}\text { Size of boiler } \\
(\mathbf{k g} / \mathbf{h})\end{array}$ & \multirow{2}{*}{$\begin{array}{c}\text { Steam load } \\
(\mathbf{k g} / \mathbf{h})\end{array}$} & $\begin{array}{c}\text { Input energy } \\
(\mathrm{Kw})\end{array}$ & \multicolumn{2}{|c|}{ Stack } & efficiency \\
\cline { 5 - 7 } & 90720 & 78471.41 & 84580.31 & 143.6 & 1.95 & 86 \\
\hline 1 & 90720 & 77786.49 & 53514.77 & 322.3 & 2.1 & 77.9 \\
\hline 2 & 45360 & 0 & 0 & 0 & 0 & 0 \\
\hline 3 & 22. & 15625749 & 138095408 & 21. & 20. & 19. \\
\hline
\end{tabular}


Table 9. Experimental result

\begin{tabular}{|c|c|c|c|c|c|c|}
\hline \multirow{2}{*}{$\begin{array}{c}\text { Number of } \\
\text { boiler }\end{array}$} & \multirow{2}{*}{$\begin{array}{c}\text { Size of boiler } \\
(\mathrm{kg} / \mathrm{h})\end{array}$} & \multirow{2}{*}{$\begin{array}{c}\text { Steam load } \\
(\mathrm{kg} / \mathrm{h})\end{array}$} & \multirow{2}{*}{$\begin{array}{c}\text { Input energy } \\
(\mathrm{Kw})\end{array}$} & \multicolumn{2}{|c|}{ 'Stack } & \multirow[t]{2}{*}{ efficiency } \\
\hline & & & & Temperature & Output Oxygen (\%) & \\
\hline 1 & 90720 & 79931.28 & 84437.47 & 149.1 & 2.1 & 85.7 \\
\hline 2 & 90720 & 77350.36 & 54321.63 & 336.2 & 2.05 & 78.2 \\
\hline 3 & 45360 & 0 & 0 & 0 & 0 & 0 \\
\hline Sum & 26. & 156681.64 & 138759.1 & 25. & 24. & 23. \\
\hline
\end{tabular}

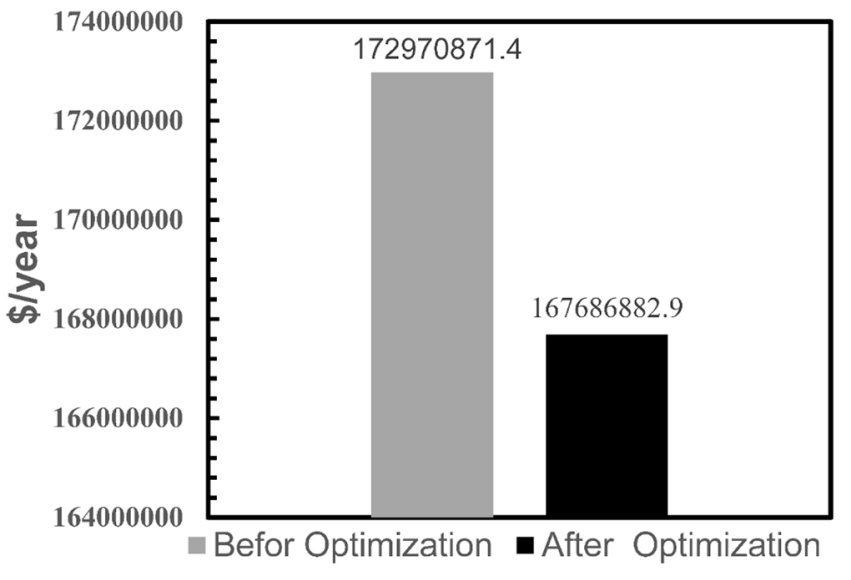

Figure 5. Flowchart for opitmal utility system optimization.

negligible in this research. The deviation of numerical and experimental result in excess air is negligible.

Thus, the results of MILP model are reliable in this article.

The result shows that the use of two boilers is enough to provide the steam which is used in cooking plants. It means that fuel consumption and water consumption can decrease to have a cooking plant which emits a few greenhouse gases. In addition, the increment of stack temperature shows that using temperature is possible to preheat the water. This is due to the declining of fuel consumption which should be used for water heating in boilers. As a result, operating cost can decline moderately in cooking plant.

The economic feasibility of steam network optimization is presented in Figure 4. The operating cost is reported before and after optimization in Figure 4. It is calculated by using experimental result, numerical result and it is calculated for 8500 hours per annum. Figure 5 shows that the operating cost reduces up to $167686882.9 \$$ per annum. The period of return on investment is less than a month since the cost of simulation and instruments are negligible when cost of experimental and numerical investigation are compared with the reduction of operating cost. Thus, optimization is recommended to be performed in petrochemical industry, heating and air-conditioning system in different commercial building and hospitals in Iran since the fuel waste is relatively high in Iran.

\section{Conclusion}

Experimental and numerical methods are used to optimize the steam load, excess air, stack temperature and efficiency of boilers. The interaction between the algorithm and model structure in the calculation can effectively ensure the feasibility of configuration and improves the computational and empirical efficiencies. This method can be used as an alternative method for optimization of utility system. However, to find the optimal solution, The BEOT model should develop with other items which can be effective on the water consumption and energy input in boilers. Improving the efficiency of evolution algorithm for solving chemical engineering and energy engineering problems can be considered as future project.

\section{Reference}

1. Varbanov PS, Doyle S, Smith R. Modelling and optimization of utility systems. Chemical Engineering Research Design. 2004; 82(5):561-78. https://doi.org/ $10.1205 / 026387604323142603$

2. Papoulias SA, Grossmann E. A structural optimization approach in process synthesis. Computers and Chemical Engineering. 1983; 7:695-706. https://doi.org/10.1016/ 0098-1354(83)85022-4

3. Luo X, Zhang B, Chen Y, Mo S. Operational planning optimization of steam power plants considering equipment failure in petrochemical complex. Applied Energy. 2013; 112:1247-64. https://doi.org/10.1016/j.apenergy.2012.12.039

4. Luo X, Hu J, Zhao J, Zhang B, Chen Y, Mo S. Multi-objective optimization for the design and synthesis of utility system with emission abatement technology concerns. Applied Energy. 2014; 136:1110-31. https://doi.org/10.1016/j. apenergy.2014.06.076 
5. Zho H, Rong G, Yiping F, Dong X. Integration optimization of production and utility system for refinery-wide planning. IFAC Proceeding. 2014; 47(3):9599-604. https:// doi.org/10.3182/20140824-6-ZA-1003.02128

6. Luo X, Zhang B, Chen Y, Mo S. Modelling and optimization of a utility system containing multiple extractions steam turbines. Energy. 2011; 36:3501-12. https://doi.org/10.1016/j.energy.2011.03.056

7. Li Z, Du W, Zhao L, Qian F. Synthesis and optimization of utility system using parameter adaptive differential evolution algorithm. Chinese Journal Chemical Engineering. 2015; 23(8): 1350-6. https://doi.org/10.1016/j.cjche.2015.01.013

8. Pouyan Rad M, Khoshgoftar Manesh MH, Rosen MA, AmidpourM.Newprocedurefor designandexergoeconomic optimization of site utility system considering reliability. Applied Thermal Engineering. 2016; 94:478-90. https://doi. org/10.1016/j.applthermaleng.2015.10.091

9. Yeo YK, Roh HD, Kim IW, Moon I, Chung Y. Optimal operation of utility system in petrochemical plants. Korean Journal of Chemical Engineering. 2003; 20(2):200-6. https://doi.org/10.1007/BF02697229

10. Oh SH, Yeo YK. Modelling and simulation of motor/ turbine process in utility plant. Korean Journal of Chemical Engineering. 2008; 25(3):409-18. https://doi.org/10.1007/ s11814-008-0069-3

11. Lin Z, Zheng Z, Smith R, Yin Q. Reliability issues in the design and optimization of process utility systems. Theoretical Foundation Chemical Engineering. 2012; 46(6):747-54.

12. Yin H, Dai W. Optimal operational planning of steam power system using an IPSOSA Algorithm. Journal of Computer Systems Sciences International. 2010; 49(5):750-6.

13. Zeqiu L, Liang Z, Wenli D, Feng Q. Modelling and optimization of the steam turbine network of an ethylene plant. Chinese Journal of Chemical Engineering. 2013; 21(5):520-8.https://doi.org/10.1016/S1004-9541(13) 60530-3

14. Zhu Q, Luo X, Zhang B, Chen Y, Mo S. Mathematical modelling, ventilation and operation optimization of industrial complex steam turbine network - methodology and application. Energy. 2016; 97:191-213. https://doi. org/10.1016/j.energy.2015.12.112

15. Li Z, Du W, Zhao L, Qian F. Modelling and optimization of a steam in a chemical plant containing multiple direct drive steam turbines. Industrial Engineering Chemical Research. 2014; 53(27):11021-32. https://doi.org/10.1021/ie402438t

16. Lyer RR, Grossmann IE. Optimal multi-period operational planning for utility systems. Computers Chemical Engineering. 1997; 21(8):787-800. https://doi.org/10.1016/ S0098-1354(96)00317-1

17. Lyer RR, Grossmann IE. Synthesis and operational planning of utility system for multi-period operation.
Computer Chemical Engineering. 1998; 22(7-8): 979-93. https://doi.org/10.1016/S0098-1354(97)00270-6

18. Zhang BJ, Liu K, Luo XL, Chen QL, Li WK. A multi-period mathematical model for simultaneous optimization of materials and energy on the refining site scale. Applied Energy. 2015; 143:238-50. https://doi.org/10.1016/j. apenergy.2015.01.044

19. Zhang BJ, Luo XL, Chen XZ, Chen QL. Coupling process plants and utility systems for site scale steam integration. Industrial Engineering Chemical Research. 2013; 52(41): 14627-36. https://doi.org/10.1021/ie401952h

20. Gibson CA, Meybodi MA, Behnia M. Optimisation and selection of a steam turbine for a large scale industrial CHP (Combined Heat and Power) system under Australia's carbon price. Energy. 2013; 61:291-307. https:/doi.org/ 10.1016/j.energy.2013.08.045

21. Caballero JA, Navarro MA, Ruiz-Femenia R, Grossmann IE. Integration of different models in the design of chemical process: Application to design of power plant. Applied Energy. 2014; 124:256-73. https://doi.org/10.1016/j. apenergy.2014.03.018

22. Martelli E, Elsido C, Mian A, Marechal F. MINLP model and two-stage algorithm for the simultaneous synthesis of heat exchanger networks, utility systems and heat recovery. Computer Chemical Engineering. 2017; 106: 663-89. https://doi.org/10.1016/j.compchemeng.2017. 01.043

23. Goh WS, Wan YK, Tay CK, Ng RTL, Ng DKS. Automated targeting model for synthesis of heat exchanger network with utility systems. Applied Energy. 2016; 162:1272-81. https://doi.org/10.1016/j.apenergy.2015.04.113

24. Luo X, Huang X, EI-Halwaqi MM, Ponce-Ortega JM, Chen Y. Simultaneous synthesis of utility system and heat exchanger network incorporating steam condensate and boiler feedwater. Energy. 2016; 113:875-93. https://doi. org/10.1016/j.energy.2016.07.109

25. Ahn Y, Han J. Economic optimization of integrated network for utility supply and carbon dioxide mitigation with multi-site and multi-period demand uncertainties. Applied Energy. 2018; 220:723-34. https://doi.org/10.1016/j. apenergy.2018.02.129

26. Ma J, Chang C, Wang Y, Feng X. Multi-objective optimization of multi-period interplant heat integration using steam system. Energy. 2018; 159:950-60. https:// doi.org/10.1016/j.energy.2018.06.217

27. Suciu R, Stadler P, Girardin L, Maréchal F. Multi-period multi-time optimisation of $\mathrm{CO}_{2}$ based district energy system. Computer Aid and Chemical Engineering. 2018; 43:1057-62.https://doi.org/10.1016/B978-0-444-642356.50185-6

28. Fazlollahi S, Becker G, Ashouri A, Maréchal F. Multiobjective, "multi-period optimization of district energy 
system: IV-A case study. Energy. 2015; 84:365-81. https://doi.org/10.1016/j.energy.2015.03.003

29. Fazlollahi S, Becker G, Guihard M, Marechal F. Multiobjective, multi-period optimization of district energy systems: Networks design. Computer-aid and Chemical Engineering. 2013; 32:463-8. https://doi.org/10.1016/B9780-444-63234-0.50078-6

30. Mete E, Turkay M. Energy network optimization in an oil refinery. Computer-aided Chemical Engineering. 2018; 44:1897-902. https://doi.org/10.1016/B978-0-444-64241-7. 50311-6

31. Zhao H, Rong G, Feng Y. Multiperiod planning model for integrated optimization of a refinery production and utility system. Industrial Engineering Chemical Research. 2014; 53(41):16107-22. https://doi.org/10.1021/ ie $502717 \mathrm{e}$

32. Zhang JD, Rong G. An MILP model for multi-period optimization of fuel gas system scheduling in refinery and its marginal value analysis. Chemical Engineering Research Design. 2008; 86(2):141-51.https://doi.org/10.1016/j.cherd. 2007.11.002
33. Micheletto SR, Pinto JM. Operational optimization of the thermoelectric system of an oil refinery. Computer-aid Chemical Engineering. 2006; 21:1839-44. https://doi.org/10.1016/S1570-7946(06)80315-9

34. Cui Y, Geng Z, Zhu Q, Han Y. Review: Multi-objective optimization methods and application in energy saving. Energy. 2017; 125:681-704. https://doi.org/10.1016/j. energy.2017.02.174

35. Sun L, Gai L, Smith R. Site utility system optimization with operation adjustment under uncertainty. Applied Energy. 2017; 186:450-6. https://doi.org/10.1016/j. apenergy.2016.05.036

36. Tarighaleslami AH, Walmsley TG, Athkins MJ, Walmsley MRW, Neale JR. Utility exchanger network synthesis for total site heat integration. Energy. 2018; 153:1000-15. https://doi.org/10.1016/j.energy.2018.04.111

37. Department of Energy Engineering. Boiler efficiency measurement. Budapest University of Technology and Economics; 2018. p. 1-46.

38. Iranian National Gas Corporation. 2014. http://igs.nigc.ir/ STANDS/IGS/M-CH-033(1).PDF 